This item was submitted to Loughborough's Research Repository by the author.

Items in Figshare are protected by copyright, with all rights reserved, unless otherwise indicated.

\title{
Fans, racism and British football in the 21st century: the existence of a colour-blind ideology
}

PLEASE CITE THE PUBLISHED VERSION

http://dx.doi.org/10.1080/1369183X.2013.777524

PUBLISHER

(c) Taylor \& Francis

VERSION

AM (Accepted Manuscript)

LICENCE

CC BY-NC-ND 4.0

REPOSITORY RECORD

Cleland, Jamie, and Ellis Cashmore. 2019. "Fans, Racism and British Football in the 21st Century: The Existence of a Colour-blind Ideology". figshare. https://hdl.handle.net/2134/12124. 
This item was submitted to Loughborough's Institutional Repository (https://dspace.lboro.ac.uk/) by the author and is made available under the following Creative Commons Licence conditions.

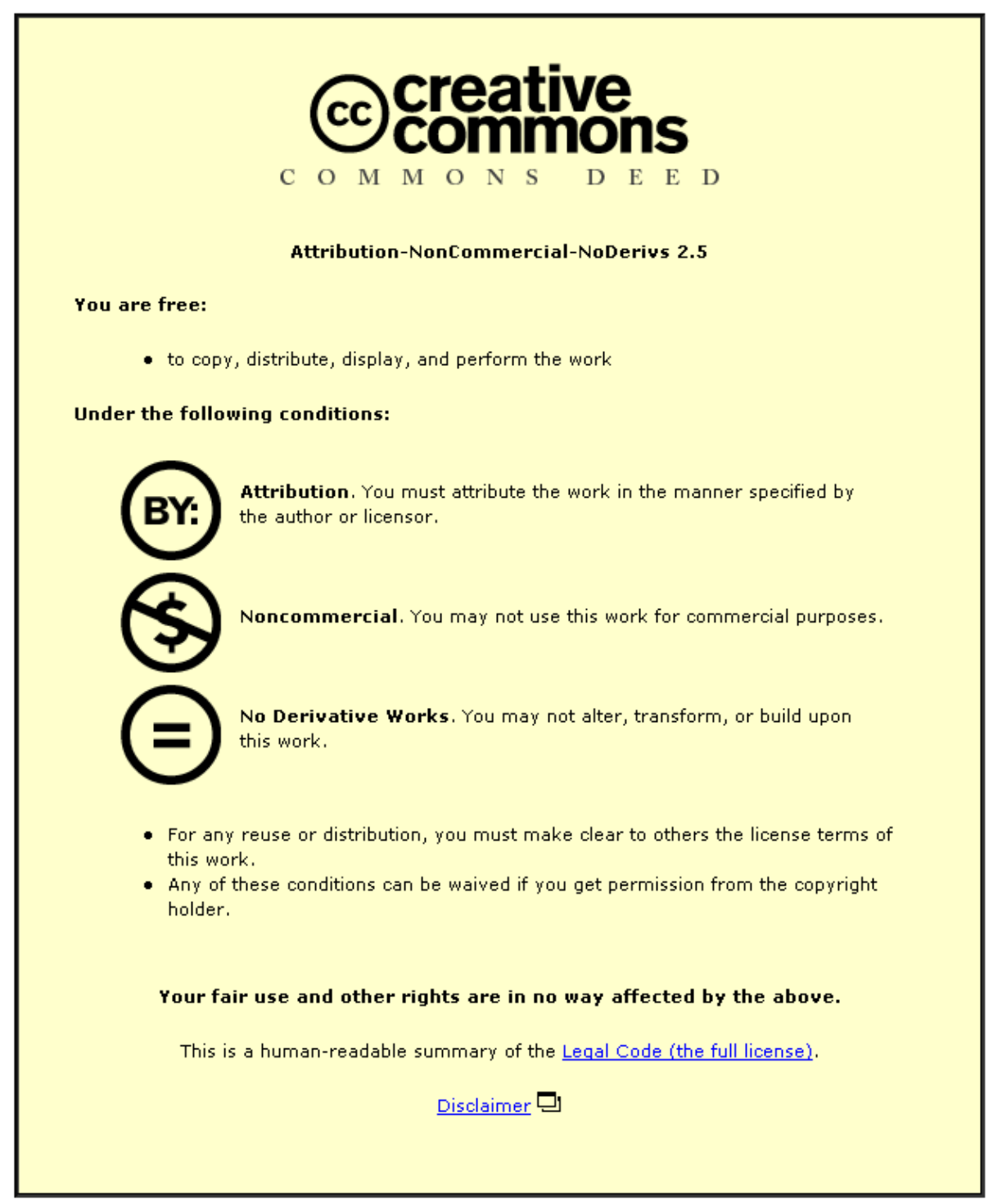

For the full text of this licence, please go to: http://creativecommons.org/licenses/by-nc-nd/2.5/ 


\title{
Fans, Racism and British Football in the $21^{\text {st }}$ Century: The Existence of a 'Colour-Blind' Ideology
}

\begin{abstract}
This article draws on 2,500 responses from association football (soccer) fans to an anonymous online survey posted from November 2011 to February 2012 examining the extent of racism in British football. The overall findings are that half of all fans are still witnessing or experiencing some form of racism. Despite the creation of anti-racist initiatives, such as Kick It Out, and a reduction in overt chanting, there exists a 'colour-blind' ideology amongst the game's governing bodies and anti-racist organisations as the extent of the problem is largely being ignored. Fans call for a long-term focus on anti-racism based on engagement and education within a greater range of social settings and, short-term, the implementation of more severe punishments by the game's governing bodies to eliminate racist behaviour amongst fans, players and clubs. For current and ex-players that continue to receive racial abuse through social media sites like Twitter, fans urge them to report it and place these matters in the hands of the police.
\end{abstract}

\section{Keywords: Football; racism; fans; anti-racism; Kick It Out; social media}

\section{Football, 'Race’ and Racism}

When the Football Association (FA) was formed in 1863 to regulate the national game, a pattern emerged that lasted for over 100 years; namely, that it was a game played and followed by white working-class men, mostly though not exclusively from the growing number of industrial cities being created. Black players did have a presence in professional football (professionalism was legalised by the FA in 1885), such as Arthur Wharton in the late nineteenth century, Walter Tull in the early twentieth century and Charlie Williams in the 1950s, but the overwhelming pattern was that the low number of black players meant white supporters felt no threat to their racial dominance.

The playing environment began to change, however, with an increasing number of black players from the late 1970s and early 1980s. British-born black footballers including Viv Anderson, Garth Crooks, Cyrille Regis, Laurie Cunningham and John Barnes became prominent figures, but they were not well received by sections of the largely populated white supporter base (even by some of those supporting the team they played for). Although some supporters accepted black players, other sections of the football crowd - at the time including those affiliated with neo-Nazi and National Front organisations - were less welcoming with 
frequent monkey noises, overt racial chants and the throwing of bananas aimed in their direction (Back, Crabbe and Solomos, 2001; Garland and Rowe, 2001).

Not long after the launch of the Premier League in 1992, a national anti-racist initiative began in 1993. Originally called 'Let's Kick Racism Out Of Football' (in 1997 it changed to 'Kick It Out'), the high-profile campaign promised a targeted approach to racism and racist language in football as well as a wider focus on race equality. Part of this campaign was the installation of prescriptive written codes of conduct supporters had to adhere to whilst in the stadiums they entered. In fact, the focus on race at this time was not just confined to football. The most prominent was the Macpherson Report (1999), which resulted from a public inquiry into the brutal murder of black teenager Stephen Lawrence in 1993. This report sought to change race relations in the United Kingdom (UK) and was quickly followed by the updated Race Relations (Amendment) Act in 2000 which placed a greater emphasis on public authorities to promote race equality. ${ }^{\mathrm{i}}$

At the same time, British football started to recruit a number of black players from overseas as the game, helped by the exposure generated by satellite television (most notably BSkyB), became more global in its scope. Complementing the existence of an increasing number of black British players, Dutchman Ruud Gullit, Ghanaian Tony Yeboah, Senegalese-born Patrick Vieira and many others began to ply their trade in the fast-evolving Premier League (a process of recruitment that has continued ever since). As teams became transnational and the spectacle of football improved, this all helped to paint a picture of declining racism across British football; the perception being that the success of black players helped to change the culture of football fandom.

During October 2011, two high-profile incidents of racism occurred on-the-field during two separate Premier League fixtures. Firstly, in a match between Liverpool and Manchester United at Anfield, Luis Suarez (playing for Liverpool) was eventually banned for 
eight matches and fined $£ 40,000$ for using racial terms towards Patrice Evra (playing for Manchester United). A week later, in a match between Queens Park Rangers and Chelsea at Loftus Road, there was another racist incident between Chelsea captain, John Terry, and Queens Park Rangers defender, Anton Ferdinand. In a case that lasted nearly a year, Terry was cleared of a racist insult charge at Westminster Magistrates' Court in July 2012, but in September 2012 was banned for four matches by the FA and fined $£ 220,000$ for the use of racist language towards Ferdinand. Drawn to play against each other in the third round of the FA Cup in January 2012, it was revealed the day before the game that Ferdinand had been sent a bullet through the post to the club’s training ground.

These on-the-field incidents were matched by a growing number taking place on prominent social media sites like Twitter, including a number of racist messages directed at ex-footballer and now media pundit, Stan Collymore, as well as other current players (including England and Manchester City defender Micah Richards, Chelsea midfielder Mikel and West Ham forward Carlton Cole). Although some black players continue to remain silent on racism, what has changed is that Ferdinand, Evra and Collymore became exceptions to the rule as they reported racism directed at them to the relevant authorities; in Collymore's case, the police. Thus, and possibly in agreement with King's (2004) argument, black players have often succeeded in their careers despite racism. Some black footballers choose to 'play the white man', whilst others do not.

Looking across football, it is clear that the game remains a white institution: from the heads of FIFA (Fédération Internationale de Football Association), UEFA (Union of European Football Associations) and the FA through to club owners, directors, players, referees and fans. Examples of racial inequality like this have led to critical race scholars challenging dominant discourses and policies when examining social relations in society. One particular approach, originating from legal studies in the United States, Critical Race Theory 
(CRT), is increasingly being applied to other nation states, such as the UK (Hylton, 2005, 2010; Burdsey, 2007, 2011). Arguing for greater promotion of racial equality within sport, Hylton (2005: 85) states that 'race' continues to be marginalised and a CRT approach 'challenges traditional dominant ideologies around objectivity, meritocracy, colour-blindness, race neutrality and equal opportunity'. Adopting a CRT perspective when analysing 'race' and racism in British football, Burdsey (2007: 9) illustrates that it 'enables us to understand that dominant claims that football is 'colour-blind' or meritocratic are actually a means of sustaining white hegemony in the structures and subcultures of the professional game'.

One of the leading scholars on 'colour-blind' racism, Eduardo Bonilla-Silva (2001, 2006), suggests that the Civil Rights movement in America in the 1960s created a shift where white privilege was once 'achieved through overt and usually explicit racial practices', to one where 'today it is accomplished through institutional, subtle and non-racial means' (2001: 12). For Bonilla-Silva, the theory that we live in a 'colour-blind', non-racist society, needs contesting and he provides empirical evidence of this in his work. According to Burdsey (2011: 7), the belief that racism has been eradicated from much of football allows it to operate 'in complex, nuanced and often covert ways that go under the radar of football authorities and beyond the capacities of anti-racist groups'. Thus, for Burdsey (2007, 2011), a 'colour-blind' ideology permeates through British football as the relevant authorities or personnel refuse to acknowledge the extent to which racism remains present. Indeed, research by Cashmore and Cleland (2011) looked at 1,000 fans' views towards the lack of black managers in English football and found that 56 per cent believe racism operates in the boardroom. Some fans accuse directors and executives of clubs of deliberate discrimination, whilst most supporters argue institutional racism exists as ‘colour-blind' assumptions about the capabilities of a black person are not challenged, and thus negative stereotypes continue to circulate. This occurs despite the fact that, in the UK in 2012, 25 per cent of professional 
footballers are from a black or minority ethnic (BME) background (Merrick, Brady and Youde, 2012). Indeed, this lends further support to the argument by Hylton (2010) that a 'colour-blind' approach continues to reinforce racial disadvantage. The latest example of this can be seen in comments made by Dave Whelan, the current chairman of Wigan Athletic, in October 2011 (Guardian, 2011):

I think we should forget colour and...you know, it doesn't bother anybody. Sometimes a footballer, when they're playing at such a level, with the stress there is...if they call somebody white, if they call somebody black, you've just got to get on with it...You know, I think the players who come and complain, sometimes they are a little bit out of order.

Examples like this and the recent incidents stated earlier provided the research with its empirical focus: do fans think that there is a wider problem of racism in British football than is currently being reported? Not surprisingly, academic attention has focused on the centrality of racism within the structure of football (Back et al. 2001; Burdsey, 2007, 2011; Garland and Rowe, 2001; King, 2004; Ruddock, 2005; Saeed and Kilvington, 2011; Thomas, 2011). For example, Back et al. (2001) and Burdsey (2011) have argued that the focus on racism by the relevant organisations is very superficial, selective and ultimately 'colour-blind'. Clearly some progress has been made through the growing number of black players plying their trade across Europe as well as the general decrease in overt racism, but these organisations are often reluctant to engage with football fans' individual experiences of going to watch football. There are examples of scholars who have looked at fans' views towards racism in football, but these tend to be club or location specific (such as Fawbert, 2011; Millward, 2008a; Thomas, 2011). By investigating the experiences and opinions of football fans from across the country, this article looks to challenge the dominant position that racism has largely been eradicated and shall provide large-scale empirical evidence outlining how the game’s governing bodies and anti-racist organisations can be accused of being 'colour-blind' to the problem of racism that remains. 


\section{Method}

The Internet is quickly developing into an important component of social science research due to the potential sample size and speed with which data can be collected and analysed (Cashmore and Cleland, 2011; Gibbons and Nuttall, 2012; Millward, 2008b; Ruddock, 2005). As the area under investigation in this article was of a sensitive nature, an anonymous online survey was created to gather the data as it was deemed more likely to encourage frank and honest accounts than face-to-face survey work (and thus avoid the potential bias of social desirability). By constructing an online survey, the emphasis was to remove the motivation to lie, or to repeat the survey, as no prizes were offered by doing so.

In previous research, a partnership has been built up with fans' forum website editors (now totalling over 80 and spread all over the UK), who allow cultural entrée (Kozinets, 2010) into their online community where a paragraph about the research in question and a link to the online survey (www.topfan.co.uk) is posted on one of the discussion boards. ${ }^{\text {ii }}$ Most of the posts were included in the 'off topic' discussion board on each website, so not to disrupt the discussions taking place on the main message boards. Once a researcher has access, Millward (2008b) has debated whether they should make themselves known during the research process. This was felt necessary as the intention was for fans to provide an honest narrative so, in the opening post, I stated I was an academic looking to gather fans' views towards racism in football via an online survey. ${ }^{\mathrm{iii}}$ In aiding the data collection process, on a large number of occasions, the original post was also supported by a reply from the website moderator, stating that their permission had been approved and this type of support is likely to have increased the number of responses (Gibbons and Nuttall, 2012). ${ }^{\text {iv }}$ Due to the anonymous nature of the research, for those fans that completed the survey, a message was included at the end which stated that by clicking submit they were giving consent for their views to be used. 
To collect the necessary data, the research was conducted over two phases between November 2011 and February 2012. Phase one was in response to the accusations and stories of racism in football discussed earlier and asked the participants their views on a range of topics including whether these were isolated cases, the role of Kick It Out, UEFA and FIFA in combatting racism and the role of social media (such as Twitter). Phase two then asked the participants whether they had seen or witnessed any incidents of racism within football and the questions were related to the age that they gave at the beginning of the survey. For example, older fans born before the 1980s (aged 30+) would have been familiar with the habitual taunting of black players in the 1980s, and could reflect on whether there has been a decline in conspicuous racism through the 1990s and into the twenty-first century. Fans born in the 1980s (aged between 21-30) would have grown up during the formation of the Premier League during the 1990s and the rise of marketable football, broadcast by BSkyB, and gentrified as sport for all classes into the twenty-first century. Younger fans could concentrate on more recent experiences. In total, 2,500 responses were received, with 1,204 completing phase one and 1,296 completing phase two. 84 per cent of the participants were male with 16 per cent female, with 95 per cent white and 5 per cent BME (figures that are similar to those published by the annual Premier League survey). ${ }^{\mathrm{v}} 12$ per cent of the participants were aged under 19, 22 per cent were aged 20-29, 22 per cent were aged 30-39, 21 per cent were aged 40-49, 17 per cent were aged 50-59 and 6 per cent were aged 60+.

Despite the use of pseudonyms on message boards, anonymity amongst posters cannot be assumed, as previous research has found that some members of the online fan community actually know each other (Millward, 2009). Here, posters could lie or exaggerate their true feelings in the hope of impressing or influencing fellow posters whilst, conversely, the same could happen amongst those who do not know each other (Gibbons and Nuttall, 2012). Therefore, despite the significant number of posts received, this article makes no 
suggestion that it is representative of all football supporters. However, the large sample still represents a significant composition of views that fans have towards racism in football. Furthermore, although there is no way of knowing whether those who responded to the posts were actually supporters of the clubs where cultural entrée was gained, the research objective was not to test fans of a particular club but to get them to express their honest views.

Although the sample has an in-built bias as only those who have access to the Internet can complete the survey, it was felt that in 2011-12 when access to the Internet is available at most public places and on a significant number of smartphones, this was an acceptable bias. As a self-selecting survey, the research did not suffer from more traditional sampling errors as participation was voluntary and anonymous. However, as suggested by Gibbons and Nuttall (2012), self-selection does allow for an inflated bias and that is why such a large amount of responses were collected. To limit the bias where only those engaged in fans' forums had the opportunity to complete the survey, at certain times the research was distributed to the local and national media through press releases as well as live media interviews to try and advertise the website to as wide an audience of football supporters as possible. ${ }^{\text {vi }}$ It was also advertised on Topfan's Twitter and Facebook pages.

Across both phases a mixed method of analysis took place. This involved a statistical breakdown of the data as well as a thematic analysis of the open-ended responses. To minimise subjectivity when examining the open-ended data, two social science researchers went through the data separately to examine for evidence of patterns, commonalities and differences across the responses (Miles and Huberman, 1984). Through this inductive approach, multiple levels of the open-ended data were broken down into larger theoretical categories and consistent themes then emerged. 


\section{Results}

British football is more multicultural than ever, but even allowing for some sampling bias, the results are unequivocal. 83 per cent of the participants stated that racism has never left British football, despite the introduction of the Premier League and billions of pounds worth of investment from BSkyB to turn football into the world's most popular sport. Between 1990 and 1999, 67 per cent of those who watched football at this time witnessed or experienced racism; between 2000 and 2009, 61 per cent; and 50 per cent since 2010. Although this suggests a decline, it is not as steep as many, including Kick It Out, have claimed. What has become evident, however, is an increasingly 'colour-blind' approach towards the existence of racism by the game’s governing bodies and anti-racist organisations. By way of illustration, the chairman of Kick It Out, Lord Ouseley, stated in 2012: 'Going to watch football in the early 1990s was an unpleasant experience...There have been huge strides forward since then, and the nastiness and the worst excesses of both abuse and violence have to a large extent gone’ (Merrick et al. 2012). As suggested earlier, public denials like this are a key element of the work of Bonilla-Silva (2001, 2006), who contests the perception that we live in a 'colourblind', non-racist society. What is presented here supports this and Burdsey's (2011: 7) argument that the game's governing bodies and anti-racist organisations collectively fail 'to acknowledge the extent to which racism actually continues to exist and the various ways in which it manifests itself'.

\section{Racism has never left football}

For Bonilla-Silva (2006), racism is structural and although overt expressions of racial resentment have decreased, more covert and nuanced forms of racism now exist that allows whites to protect themselves from being labelled 'racist'. Indeed, the results within this study found that although 'older' and overt types of racism remain, they do so alongside increasingly more nuanced and covert forms. Examples of this were found across the data 
with this Huddersfield Town fan (white, male, aged 40-49) typifying the mood of most participants who could judge the environment over several decades:

Racism has always been present in football, either directly or indirectly. At my club, black or Asian support is very much a minority in the stands and reflects the institutionalised racism within the game. Although racism appeared to be effectively dealt with under the shiny banner of Sky Sports, it was actually simply seen as inappropriate and unwanted. Therefore, racism was left below the surface where it has simmered away ever since.

Similar views were also raised by this Wolves fan (white, male, aged 40-49), who again identified 'old' types of racism, but also referred to the nuanced and more hidden nature of racism that is now present within football:

\footnotetext{
Racism in football has always been there, especially on the terraces. It may have not been so vocal since the 1980s but anyone who attends football on a regular basis will confirm racist undertones are still there and very much alive.
}

These two quotes out of the 83 per cent who stated that racism has never left British football support the views of Back et al. (2001), Burdsey (2007, 2011), Cashmore and Cleland (2011), Garland and Rowe (2001) and King (2004), who all outline how the problem of racism remains. For other fans, a softening of language is sometimes used to potentially hide their true beliefs and avoid accusations of racism (as suggested by Bonilla-Silva, 2001). Examples of this were present in the data with one Manchester United fan (white, male, aged 20-29) stating: 'There will always be racist people about...people just have to take it on the chin'. Similarly, a Derby County fan (white, male, aged 20-29) claimed: 'It has become too convenient for black players. I have been disappointed that some of the recent spats have not been dealt with behind closed doors'. Other fans try to defend the use of what they refer to as 'casual racism': 'racism is often said on the spur of the moment, much like somebody's size or hair colour' said a Nottingham Forest fan (white, male, aged 20-29), 'I believe that this kind of 'casual racism' adds to some people's belief that it is OK to say these things'.

Across the data a pattern appeared with those fans who attempted to defend what they refer to as 'casual racism' found to consistently be white, male and aged under 29. Clearly, 
these views remain culturally embedded (but not necessarily presented overtly) and for some ethnic backgrounds, racist thoughts have escalated since the turn of the twenty-first century (in particular towards Muslims and the focus on Islamophobia since 9/11). Modood (2007) argues that Islamophobia is a 'new' form of racism and, rather than concern religious intolerance and biological difference, is actually a form of cultural racism. Sharing these thoughts, Solomos and Back (1996) state how cultural racism is a product of contemporary society, where national identity and belonging are centralised to present a homogenous host culture against threats from any 'other' group. Looking at this within football, Millward (2008a) analysed the experience of former Middlesbrough player, Mido, and the reaction by fans to the Islamophobic taunts he received during a Premier League game against Newcastle United. Similarly, in Fawbert's (2011) research on West Ham United fans, an anti-Muslim sentiment is in existence, due to their increased migration into the immediate area surrounding Upton Park.

The perceived link between racism in football and racism in society football led Williams, Dunning and Murphy (1989) to suggest that it remains uncertain as to whether racist views emerge in society and are transmitted into football or whether football develops these racist thoughts as a result of the passion and prejudices that it creates within fans. In trying to justify the existence of racism within football, some participants attempt to link it into wider societal issues. 'It will happen when there is a downturn in the economy and scapegoats are needed', said this Stoke City fan (white, male, aged 20-29). A Burnley fan (white, male, aged 30-39) shared similar thoughts: 'Yes, there are racist thugs around (the English Defence League being the prime example) and that needs challenging. It's a problem for society as a whole of which football is a microscopic part'. vii

Although Burdsey and Randhawa (2012) state that more British Asians are watching Premier League football as a result of feeling safer, the narrative from those who identified 
themselves as BME highlights the 'colour-blind' ideology that exists within modern football. For some fans, the historical fear of racism at football matches remain and, for a select few, there is also the trauma of having to witness loved ones receive racist abuse: 'My exboyfriend is a professional footballer and is black' said this participant, 'Frequently I would be sat in the stands and have to listen to racist abuse being hurled at him'. Likewise, a female Sunderland fan (white, aged 40-49) stated: 'Whilst racism has not been as open in recent years, it has still existed. I say that as someone married to a black man and the parent of mixed race children who have been subject to racial abuse at football'. On this point, Burdsey (2007) and Fawbert (2011) have provided examples where Asian fans have been verbally or physically attacked in or close to football grounds and this, again, was a prominent feature of the BME data. The following narrative was the experience of this ethnic minority Bolton Wanderers fan (male, aged 50-59): 'I attended matches over 20 years ago and was subjected to racist chants (fucking paki, no black in the union jack etc.), cigarette butts thrown at me and physically attacked more than once so I stopped going'. Even BME stewards are targets for abuse, confirmed one Hearts fan (white, male, aged 30-39), who had seen a British Asian subjected to a barrage of racial epithets at a Hearts game. In fact, this was one of a number of examples from other countries within the UK that highlight how the problem is not just confined to England.

Today, any fan screaming racial abuse risks the admonition of fellow supporters, though many cite the inhibiting atmosphere of the crowd and the reluctance of stewards to intervene. Although public campaigns are present in football, the approach is very generic, rather than targeted. What fans are calling for is some recognition that a problem exists at the core of football, not on the periphery. This 'colour-blind' approach, where the level of racism is not recognised by the game's authorities, is found to create problems inside British stadiums as fans and, in some cases, stewards, are reluctant to challenge racist behaviour. As 
a Nottingham Forest fan (white, male, aged 40-49) explained: 'What is disappointing is the apparent lack of resistance from surrounding supporters (self-included - although I've not always been close enough to identify the perpetrator)', and a Norwich fan (black British, male, aged 40-49) who challenged the abuse recounts how he 'was abused by a steward who threatened police action for fan incitement'. Echoing similar experiences, a Swansea fan (white, female, aged 20-29) stated: 'Racism in stadiums is not punished properly. I've seen occasional, isolated incidents over the years and have never seen stewards take any action. If anything, enforcement is more likely to come from other fans than stewards'. Other participants argue that stewards need to take more responsibility than they do at present; a view typified by this Coventry City fan (white, male, aged 30-39): 'Stewards who work at football clubs should be properly paid and trained so that they feel confident in removing perpetrators from the stadium'.

\section{The Impact of Social Media}

Overt racist chanting may have declined since the tumultuous 1980s, but, in recent years, some fans have found a new means of expressing their views with relative impunity. Social media, particularly Twitter, has become a kind of conduit for some of the vilest racist smears conducted anonymously via smartphones and computers. The form has changed, but the content remains disconcertingly familiar, as expressed by this Ipswich Town fan (white, male, aged 30-39):

\footnotetext{
The new variable in the mix is the influence and rise of social media - thoughts that were still very much there are now being expressed due to the proliferation of devices and a lack of thought. Racists using social media were still racists before getting their paws on an iPhone or any other device.
}

Echoing these thoughts, 80 per cent of the participants stated how social media has offered an opportunity for racist thoughts to be communicated in a way that was not available to previous generations. Tweeters often shelter in anonymity, though sometimes when direct 
racist comments are made the offender is traced, as in the recent case of twenty-one year-old Liam Stacey, who was sent to prison for 56 days in March 2012 for racist comments made via Twitter towards the Bolton midfielder Fabrice Muamba, who had just suffered a cardiac arrest during an FA Cup match against Tottenham Hotspur at White Hart Lane. In the same month, twenty-one year-old Joshua Cryer was sentenced to two years community service for racially abusing Stan Collymore on Twitter after another successful prosecution. Whilst Collymore reported this matter to police, it was actually fellow 'tweeters' who alerted police to the abuse Muamba was receiving. Thus, in some circumstances, and perhaps helped by their own anonymity on social networks rather than risk any face-to-face confrontation (such as in a stadium), there is evidence that fans are now willing to act. However, the facts do not lie. Whilst there has been an increase in current and ex-players reporting racial abuse on Twitter, others choose not to do so; instead they just delete their account. The view from fans of all ages and backgrounds is clear, as typified by this Huddersfield Town fan (white, male, aged 20-29):

The use of social media allows racists to hide behind a computer screen or smartphone. This needs to be dealt with to prevent copycat behaviour from again becoming regular terrace language.

Despite the young age of those convicted of racial abuse via Twitter, a wide range of ages and backgrounds are engaging with social media sites to communicate with friends or followers. Whilst a majority adhere to the ethical rules of social media sites, fans recognise how this can be abused as it is not moderated like many other social media message boards. As a West Ham fan (white, male, aged under 19) illustrated: 'Social media have had a huge impact. People publish material that would never be permitted via written media (fanzines) or moderated message boards'. If criminal convictions continue to follow racist comments, then we are more likely to see a change of cultural communication across social media platforms. 


\section{Legislation and anti-racist initiatives}

Pointing at structural 'colour-blind' issues within football's authorities, such as those suggested by Back et al. (2001) Burdsey (2011), Garland and Rowe (2001) and King (2004), a Chelsea fan (white, male, aged 50-59) stated how the game 'is run by middle-aged white men', who fail to place racial equality at the top of their agendas; rather, the commercial nature of football and global expansion of the game has taken precedence. It is hard to disagree when faced with the reality football faces in 2012. Looking at the structure of football in a hierarchical sense, at the bottom are the fans (comprised of a white majority), whilst a white majority also exists at the top, where the key governance and organisational decisions are made (from FIFA down to club level). It is only in the middle (i.e. the playing side) that we see a blurring of different races.

For Burdsey (2007) and Cashmore and Cleland (2011), the sustainment of this white hegemonic power structure supports those who claim that football remains meritocratic or 'colour-blind' towards achieving racial equality. By way of illustration, the current president of FIFA, Sepp Blatter, was recently quoted as saying that any racist abuse on-the-field of play should end with a handshake at the end of the game (BBC Sport, 2011). High-profile comments like this continue to highlight the structural and 'colour-blind' problem of achieving racial equality; a problem that is not lost on supporters with 76 per cent saying that organisations like UEFA and FIFA seem, for some reason, reluctant to challenge racism. As one Arsenal fan (white, male, aged 40-49) stated:

The head of FIFA is so blasé about racism. This shows everything which is wrong with the game. How can you punish the players and fans harshly for racism when the head of FIFA condones it?

Fans point to more extensive and overt problems of racism across Europe, with a Fulham supporter (white, male, aged 50-59) typifying a consistent pattern of comments on this area: 'Racism is rife across the continent but it seems to be accepted. Week in, week out racist and far right banners and chants can be seen and heard in terraces in Italy, Spain and many other 
countries, yet almost nothing seems to be done about this'. 'Stronger leadership and a consistent approach to dealing with racism from the FA, UEFA and FIFA would help send a strong message that it will not be tolerated in the game', said another participant (white, male, aged 30-39), with a Barnsley fan (white, male, aged 20-29) arguing that: 'The fines given out are comical. In serious circumstances, countries should be banned from tournaments'.

The mood of the participants towards the lack of any serious action given out by organisations like UEFA regarding racist behaviour would not have improved by some of the recent fines distributed to clubs and national governing bodies. For the racist behaviour of fans towards black England players during the Euro 2012 qualifying match in Sofia in September 2011, the Bulgarian FA was fined a pitiful sum of $€ 40,000$. Unfortunately, this is just one of many 'colour-blind' examples highlighting the lack of seriousness UEFA seems to place on acts of racism. In highlighting just one other, in April 2012, Manchester City was fined $£ 24,740$ for returning to the pitch one minute late for the scheduled start of the second half of a Europa Cup match against Sporting Lisbon, whilst FC Porto was fined just £16,700 for the racist conduct by their supporters towards Manchester City players during the same competition (UEFA attributed the paltry fine due to it being the club’s first offence).

Illustrating the complacency and lack of overall consistency shown by anti-racism campaigns, particularly at an amateur level, in a recent BBC feature (BBC News, 2012), Show Racism the Red Card in Wales was just about to launch a campaign that encouraged players to report incidents of racism 'in the hope of obtaining a clearer picture of the extent of the problem'. It is worth remembering that anti-racism campaigns have been in operation for nearly twenty years, a point not lost on a number of participants:

Initiatives like Kick It Out have slowly served to highlight racism within the game but I feel it has been undermined and become nothing more than a PR t-shirt wearing exercise because of the governing bodies reluctance to take any kind of stance against racism. 
In his work on amateur and grass-roots football, Lusted (2009) states that there is a consistent 'colour-blind' failure by decision-makers in recognising the issues that remain in existence. This was also recognised by a number of participants, who stressed the significance of the grass-roots in providing both a football and social education in accepting BME players. As one participant (British Asian, male, aged 30-39) stated:

\begin{abstract}
Working as a sport development officer in a high ethnically populated area of London, it's clear that the lack of any real directive from the FA etc. is having a negative influence. I want to recruit more people from ethnic backgrounds to play football, but they are reluctant and who can blame them?
\end{abstract}

At a professional level in Britain there has been the development of more local-based initiatives like Port Vale's 'Valiants Against Racism' and to an extent these have been successful in helping to further reduce overt acts of racism inside football stadiums (Bradbury, 2011). Although it has been argued that professional clubs need to demonstrate more tangible commitments to anti-racism campaigns, some fans acknowledge the work that Kick It Out has done in reducing overt racism. However, fans, including this Cardiff City supporter (white, male, aged 40-49), are challenging them to go further:

\footnotetext{
Much of the work done by organisations such as Kick It Out has not changed attitudes at source, and has driven racist opinion underground to an extent. Methods for actively changing opinion (rather than merely burying it) are far more difficult to propose, but societal change cannot happen overnight.
}

Scholars are also divided as to the success of Kick It Out. Gardiner and Welch (2011: 227), for example, claim that:

\begin{abstract}
The Kick It Out campaign has been a crucial component in promulgating education and attitude changing initiatives...Whilst racist sentiments can still be overheard in conversations between football supporters, there is an inhibition against voicing racist attitudes more audibly because of the adverse impact this would have on players in the supporters' teams.
\end{abstract}

The data here would question these views as 79 per cent of the participants stated that Kick It Out has only been partially effective in addressing its aims to tackle racial inequality. This was just another example of supporters accusing anti-racist organisations of adopting a 'colour-blind’ ideology towards racial equality. Indeed, Randhawa (2011: 245) is quite 
critical of Kick It Out by stating how it 'has failed to create positive, sustained change and has simply been satisfied with the insignificant success of finite exposure' over its twentyyear history.

Despite the claim that the creation of the Premier League has changed the landscape of English football, high-profile incidents of racism are now being reported on a regular basis. Referring to the example of Oldham Athletic player, Tom Adeyemi, who was racially abused at an FA Cup match against Liverpool at Anfield in January 2012, this Liverpool fan (white, male, aged 40-49) said it was not an isolated case:

For too long incidents like this have gone unpunished by stewards at the game, ignored by the club when I raised it and Kick It Out are living in cloud cuckoo land if they think they are tackling racism effectively.

Action towards racial chanting was published in 1991 with the creation of the s.3 Football Offences Act (FOA), subsequently amended by s.9 Football (Offences and Disorder) Act (FODA) in 1999. Gardiner and Welch (2011) note that one of the key amendments between both acts concerns the 'individualisation' of an offence. Before the creation of FODA, any offence required racist chanting to be 'in concert' with other fans. Despite FODA now making any offence more individual-based, it still has to amount to some form of chanting; single abusive shouts are not in breach of the act. Granted British football does not witness the kinds of collective monkey chants directed at black players in Italy, Spain or parts of Eastern Europe, but does that excuse the continued existence of racism in this country? Legislation and anti-racist initiatives have been good in preventing overt racist chanting, but examples remain, even in 2012. In an FA Cup third round match between Nottingham Forest and Leicester City in January 2012, a number of participants referred to a song directed at the Leicester supporters of 'you used to be English, but not anymore', in direct reference to the increasing ethnic population in the city of Leicester. This was not an isolated example in the responses; others given on more than one occasion included Everton fans singing 'Everton 
are white' or Sheffield Wednesday fans singing 'I'd rather be a paki than a Blade' - a reference to the nickname of their local rivals, Sheffield United. Hence, collective racist chanting, whilst reduced has not been fully eradicated.

So, how could this 'colour-blind' ideology be broken? Put simply, fans are clearly demanding greater action from the game's governing bodies to implement racial equality initiatives and to take greater and more severe action towards any fan, player or club that breaks this code of conduct. 'Target the individuals rather than the clubs', said one participant. 'The clubs don't control the minds of their fans, but they can instruct stewards to throw out anyone observed making racist chants and ban them from their club' argued another. Referring to what punishments can be given out: 'Zero tolerance is the only way' said this Charlton fan (white, male, aged 20-29), 'If a player is found guilty there has to be harsh penalties similar to drug test failures. Fans should be banned for life'. The likelihood of this happening, however, is less simple. A 'zero tolerance' approach is likely to grab some headlines, but would it really eliminate racism from football grounds? As this Newcastle United supporter (white, male, aged 20-29) stated:

It is difficult to challenge the minority that have racist views...views are often present from childhood and built into the mind-set of individuals. Simply fining or even jailing them will not have much impact.

Across the data were messages like this, suggesting that we cannot expect the law, in itself, to resolve the problem of racism in football. Indeed, in his research on Islamophobia in football, Millward (2008a) also argues that coercive measures will not eliminate the problem of cultural racism. As the empirical data presented here has illustrated, racist attitudes will always find outlets in both overt and covert forms, whatever the potential punishment. 


\section{Conclusion}

Too often the relevant authorities and anti-racism organisations have failed to engage with the game's key stakeholders: the fans. Seeking the opinion of fans and using this to develop more targeted campaigns and legislation is often minimal and tokenistic and leads to racism being challenged 'only on certain terms, by particular individuals, in specific contexts' (Burdsey, 2011: 8). What has been presented in this article is large-scale empirical evidence from fans across Britain highlighting how Kick It Out, and other analogous organisations, have contributed to a culture of complacency: the interests of football's governing authorities and media corporations were best served by creating the impression that racism was a feature of football's historical landscape. The findings suggest that racism persisted; it was either disregarded or perhaps suppressed in order to give the impression that racism had been eradicated from British football.

Back et al. (2001), Burdsey (2011), King (2004) and Saeed and Kilvington (2011) have all argued that racial inequality in football is structural and institutional, but the extent of it is now becoming clear. To say that it remains a fan-player or even, in some cases, a player-player problem is both narrow and naïve. As Cashmore and Cleland (2011) have demonstrated, it is also a club-manager/coach problem. Indeed, we should also add habitual to the continued problem of achieving racial equality. Racism remains culturally embedded in the British game, and through social media and other subtle forms, it is becoming a lot harder to tackle. Individual prejudices remain and these can now be communicated in a variety of different ways than has previously been the case.

Hence, fans of all ages and backgrounds are demanding a clearer, strategic and more robust directive from FIFA and UEFA and national organisations like the FA that racism will not be tolerated across all levels of football and, when it does occur and players, managers, coaches and fans feel confident enough to report it, incidents need punishing more severely 
than is currently the case. At present, there is very little acknowledgement that racism continues to exist and, when there is overwhelming evidence of it doing so, minimal fines are given out. Although there is legislation in place to prevent acts of racism, clearly they are not even acting as a deterrent. A €40,000 to a Bulgarian or Spanish FA is unlikely to send a message that this level of behaviour will not be tolerated. At a more individual level, there is also the need for a more sustained focus on engaging with fan groups and to better educate supporters to begin tackling local and national prejudices. On this point, Gillborn (2008) has argued that a multicultural emphasis needs embedding into schools and other social settings in order to create an awareness of racial equality. Until these changes are reflected in football, the situation is likely to remain the same.

As the world's most popular sport, football has often been considered a microcosm of society, though, in this instance, it seems somewhat out-of-sync with the multicultural environment of Britain. Even allowing for the insecurity of multicultural harmony through the creation of far-right groups like the British National Party and the English Defence League, as well as sporadic outbreaks of racial incitement, British society has reached some accommodation with its ethnically diverse population and its religious plurality. Football, it seems, has not.

\footnotetext{
${ }^{\mathrm{i}}$ This subsequently became part of the 2010 Equality Act.

ii In designing a survey to test the research question, the ethical process of the British Sociological Association was adhered to - see http://www.britsoc.co.uk/media/27107/StatementofEthicalPractice.pdf, accessed 5 November, 2011.

iii A registered user on a message board can start a new conversation (or post) by creating a title and writing some text that fellow users can read and respond to. When a post receives responses by other users a 'thread' then develops.

${ }^{\text {iv }}$ Most message boards have moderators who monitor discussions taking place to ensure that each topic area and the language being used does not break the terms and conditions that users had initially accepted in order to be registered on the particular e-zine in the first place.

v See the Premier League 2008/09 survey: http://www.epfl-europeanleagues.com/changing_face.htm, accessed 20 April, 2012.

${ }^{\mathrm{vi}}$ See, for example, Shergold (2012) and Hennessey (2012).

vii Formed in 2009, the far-right political organisation opposes Islam in the UK.
} 


\section{References}

Back, L., Crabbe, T. and Solomos, J. (2001) The Changing Face of Football: Racism, Identity and Multiculture in the English Game. Oxford: Berg.

BBC News (2012) 'Racism scarring grass roots football in Wales', 11 March, http://m.bbc.co.uk/news/uk-wales-17324855?SThisEM [Accessed 11 March 2012].

BBC Sport (2011) 'Sepp Blatter says on-pitch racism can be resolved with handshake', 16 November, http://www.bbc.co.uk/sport/0/football/15757165 [Accessed 16 November 2011].

Bonilla-Silva, E. (2001) White Supremacy and Racism in the Post Civil Rights Era. London: Lynne Rienner.

Bonilla-Silva, E. (2006) Racism Without Racists: Color Blind Racism and the Persistence of Racial Inequality ( ${ }^{\text {nd }}$ edition). Boulder, CO: Lynne Rienner.

Bradbury, S. (2011) 'It's not as simple as black and white: Challenging racism in professional football through locally grounded multi-agency collaboration', in Long, J. and Spracklen, K. (eds) Sport and Challenges to Racism. Basingstoke: Palgrave, 199-213.

Burdsey, D. (2007) British Asians and Football: Culture, Identity, Exclusion. London: Routledge.

Burdsey, D. (2011) Race, Ethnicity and Football: Persisting Debates and Emergent Issues. London: Routledge.

Burdsey, D. and Randhawa, K. (2012) 'How can professional football clubs create welcoming and inclusive stadia for British Asian fans?' Journal of Policy Research in Tourism, Leisure and Events, 4(1): 105-111.

Cashmore, E. and Cleland, J. (2011) 'Why aren’t there more black football managers?' Ethnic and Racial Studies, 34(9): 1594-1607

Fawbert, J. (2011) ' Wot, no Asians?': West Ham United fandom, the cockney diaspora and the 'New' East Enders', in Burdsey, D. (eds) Race, Ethnicity and Football: Persisting Debates and Emergent Issues. London: Routledge, 175-190.

Gardiner, S. and Welch, R. (2011) 'Football, racism and the limits of 'colour blind' law?: Revisited', in Burdsey, D. (eds) Race, Ethnicity and Football: Persisting Debates and Emergent Issues. London: Routledge, 222-236.

Garland, J. and Rowe, M. (2001) Racism and Anti-Racism in Football. Basingstoke: Palgrave.

Gibbons, T. and Nuttall, D. (2012) 'Using e-surveys to access the views of football fans within online communities', Sport in Society, available via iFirst http://www.tandfonline.com/doi/abs/10.1080/17430437.2012.690401 
Gillborn, D. (2008) Racism and Education: Coincidence or Conspiracy? Abingdon:

Routledge.

Guardian (2011) 'Wigan chairman says players are 'out of order' to complain about race', 30

October,

http://www.guardian.co.uk/football/2011/oct/30/wigan-chairman-race row?newsfeed=true

[Accessed 3 November 2011].

Hennessy, M. (2012) 'Football still hasn’t kicked out racism', Irish Times, 14 January, http://www.irishtimes.com/newspaper/weekend/2012/0114/1224310234080.html [Accessed 14 January 2012].

Hylton, K. (2005) '“Race”, sport and leisure: Lessons from Critical Race Theory’, Leisure Studies, 24(1): 81-98.

Hylton, K. (2010) 'How aturn to Critical Race Theory can contribute to our understanding of 'race', racism and anti-racism in sport', International Review for the Sociology of Sport, 45(3): 335-354.

King, C. (2004) Offside Racism: Playing the White Man. Oxford: Berg.

Kozinets, R.V. (2010) Netnography: Doing Ethnographic Research Online. London: Sage.

Lusted, J. (2009) 'Playing games with "race”: understanding resistance to "race” equality initiatives in English local football governance’, Soccer and Society, 10(6): 722-739.

Merrick, J., Brady, B. and Youde, K. (2012) 'Race in Britain 2012: Has life changed for ethnic minorities?’ Independent on Sunday, 8 January.

Miles, M. and Huberman, M. (1984) Qualitative Data Analysis: A Sourcebook of New Methods, Thousand Oaks: Sage.

Millward, P. (2008a) 'Rivalries and Racisms: 'Closed' and 'open’ Islamophobic dispositions amongst football supporters'. Sociological Research Online, 13(6),

http://www.socresonline.org.uk/13/6/5.html [Accessed 12 April 2012].

Millward, P. (2008b) 'The rebirth of the football fanzine: Using e-zines as a data source', Journal of Sport and Social Issues, 32(3): 299-310.

Millward, P. (2009) Getting 'into’ Europe: Identification, Prejudice and Politics in English Football Culture. Staarbrucken: VDM Verlag.

Modood, T. (2007) Multiculturalism. Cambridge: Polity.

Randhawa, K. (2011) 'Marrying passion and professionalism: Examining the future of British Asian football', in Burdsey, D. (eds) Race, Ethnicity and Football: Persisting Debates and Emergent Issues. London: Routledge, 237-250. 
Ruddock, A. (2005) 'Let's kick racism out of football - and Lefties too!' Journal of Sport and Social Issues, 29(4): 369-385.

Saeed, A. and Kilvington, D. (2011) 'British-Asians and racism within contemporary English football’, Soccer and Society, 12(5): 600-610.

Shergold, A. (2012) 'Scourge of racism in our game never really went away', Yorkshire Post, 13 January, http://www.yorkshirepost.co.uk/sport/scourge_of_racism_in_our_game_never_really_went_a way_1_4137790 [Accessed 13 January 2012].

Solomos, J. and Back, L. (1996) Racism and Society. London: Macmillan Press.

Thomas, P. (2011) 'Marching altogether? Football fans taking a stand against racism', in Long, J. and Spracklen, K. (eds) Sport and Challenges to Racism. Basingstoke: Palgrave, 185-198.

Williams, J., Dunning, E. and Murphy, P. (1989) Hooligans Abroad: The Control of English Fans in Continental Europe, $2^{\text {nd }}$ Edition. London: Routledge. 